\title{
Producing and reproducing knowledge: Descriptive or constructive?
}

Toward a model of research production *

\section{Introduction}

In a recent paper (Knorr, 1977a) I tried to develop a notion of the research process in the natural and technological sciences which would take into account all those hermeneutical aspects commonly neglected in sociological and methodological investigations of scientific inquiries. Several authors have challenged such investigations, arguing for a more integrated picture which combines social and cognitive as well as internal and external variables (e.g. Mitroff, 1974; Bourdieu, 1975; Bloor, 1976; Mendelsohn, 1977; Latour and Woolgar, 1978). In the above paper I argued that a model of "success" which includes the relationships between scientific agents is needed to replace the presently inadequate language of truth and hypothesis testing. This paper is an attempt to outline such a model. As such, it operates in the peculiar no-man's-land between a sociology and an epistemology of science, and between the context of discovery and the context of justification. The concepts employed were chosen in order to eliminate inadequate distinctions. Integrated pictures, I think, are not created by adding disciplinary perspectives, but rather by choosing colors and forms which are free of one-sided connotation. The concept of scientific agents included in this picture draws heavily upon Bourdieu ${ }^{1}$. In sum, the theory on which this model is based is grounded in an anthropological and sociological study conducted in 1976-1977 at a major research institution in Berkeley, California. According to its official directory, this institution employs more than 300 scientists (along with the technical and service staff) working on topics in basic and applied chemical, physical, microbiological, toxicological, technological and economic research. Most of the scientists hold degrees in chemistry. My observations focused on work involved with plant proteins, an area which turned out to include a variety of questions and disciplinary approaches (generation and recovery, purification, structure, texture, biological value, protein additives, etc.). Reports, comments and citations have been taken from my notes, and their 
accuracy has been verified by the scientists involved. As befits the nature of the study, each example stands as an illustration for many others of its kind.

\section{The model}

To develop a model which conceives of scientific inquiry as a practice ${ }^{2}$ carried out by agents who collectively form the (scientific) fields which in turn determine that practice, we will begin with the relationship betwcen field and agent, proceed to the role of scientific institutions, and then move on to the question of research procedure. In agreement with Bourdieu (1975) the scientific field is seen as the locus of a competitive struggle for the monopoly of scientific credit " - that is, a symbolic capital acquired by the agents through imposition on the field of technical definitions and legitimate representations of scientific objects. Such capital is composed at the same time of scientific competence and social authority ". To establish the link between struggle in the field and the process of inquiry in the laboratory, I introduced the notion of success (Knorr, 1977a). According to the language of truth and hypothesis testing, the empirical process of inquiry is "descriptive", i.e. oriented toward correspondence with reality. However, when looking at actual laboratory practice, it becomes clear that the stakes are not defined in terms of the correspondence-theory of truth or its system-theory counterparts 5 . Instead, the process of inquiry appears to be constructive : that is, oriented toward "making things work" successfully and embedded in a reality which is highly artificial and essentially self-created. In contrast to truth, success has a definite meaning for the individual scientist: moreover, it can be operationally defined in terms of the respective agents profile of symbolic capital ${ }^{\circ}$. What counts as success is determined by the field and by the agent's position in the field. As a regulating force which structures the perceptive and conceptual classifications of the scientific agents, the field operates through its scriptures, a body of writings considered to be authoritative, and structured by indicators of differential value (the names of authors, journals and publishing companies). As a structure which orients and regulates selections, the scriptures do not function in terms of the norms and values sometimes presumed to govern science, nor are they identical to what is perceived as the common stock of knowledge in a field. The regulative force of the scriptures (and consequently the field) is transmitted by language, and rests within the conceptual schemes and categories with structure perception and association.

Like the symbolic capital of the single scientist, the scriptures are constantly reproduced through successful research practice. This practice needs a "site"; that is, a scene of action providing facilities and related to environmental factors. In most cases, this site will be the scientific organization or institution housing the laboratory. If the field is the locus for compe- 
titive struggle over the monopoly of symbolic capital, the organization is the locus for investment of this capital. As such, the institution or organization becomes the place where the capital is transformed and reproduces its value. Consequently, the opportunities, contingencies and interpretations provided by the organization (all of which constitute its oun capital) assume crucial significance. Needless to say, this capital has been built from the investments made by previous members of the organization, particularly scientists '. The relative value of the scientist's capital with respect to that of the organization will determine, through the dynamics of interaction between them, whether or not an investment is made and what form it will take ${ }^{8}$.

Unlike the businessman, the scientist who invests his capital invests "himself". Successful or unsuccessful reproduction (and accumulation!) of his credit will depend on the relationship between the agent and the new orga-

\section{Figure 1. A model of research production*}

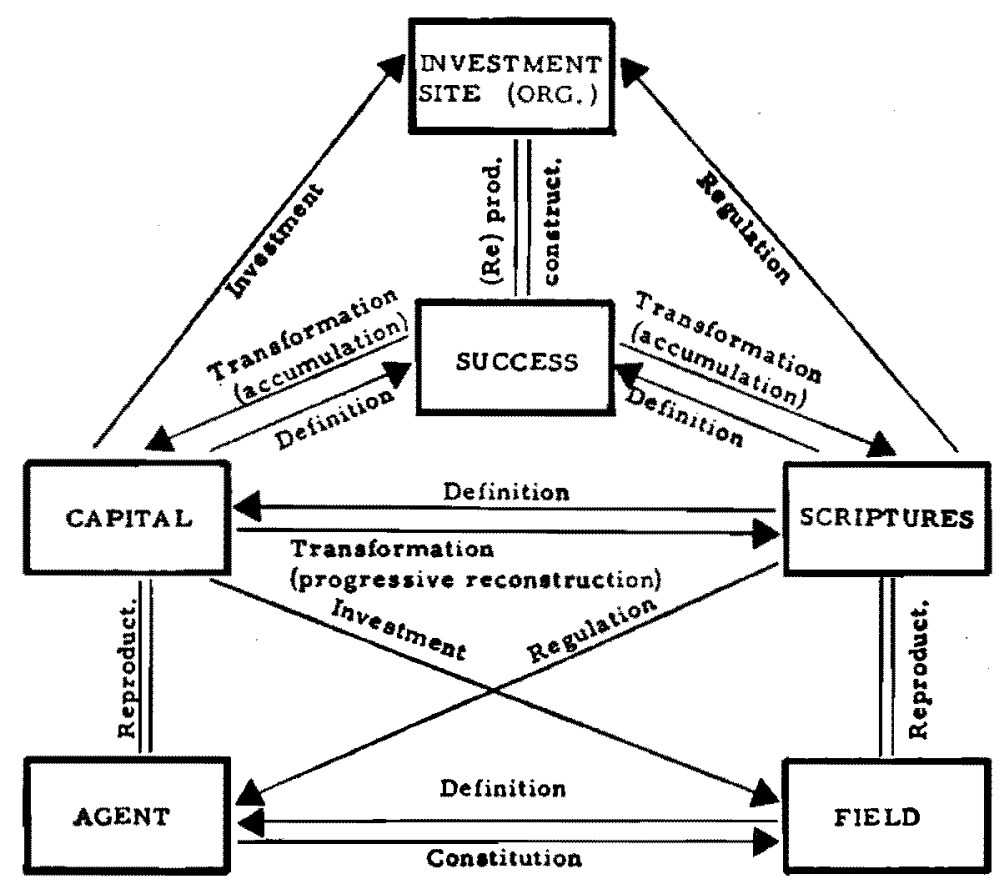

- The model represents the predominant relationships as seen from the respective entry. $E, g$. the scientitic nield is constituted by the agents, while the position of the agents is defined by the field. Double lines represent relationships of production, single arrows represent phenomena in the area of producrion, and arrows conbining relationships of transformation with those of detinition represent the level of historicity (see below). The model is proposed as an analytical tool to facilitate our understanding of the relationships between the concepts chosen and not as a somewhat mechanistic description of research production. 
nizational environment. Change (both in terms of individual accumulation of capital and a progressive reconstruction of the field) occurs when the successes of the laboratory are transformed into holdings which mark the individual curriculum and the scriptures of the field. The reconstructions are found in the writings themselves, and are promoted by a mode of production oriented toward distinctive products and ruled by negation. In science, the movement of negation (which is at the same time a struggle for the monopoly of the scriptures) results in historicity, and growth must be linked to reinvestment ${ }^{9}$. The form of such change depends upon distinguishing strategies which are themselves influenced by the field ${ }^{10}$. The basic relationships are summarized in Figure 1 above.

When considered in terms of the reproduction of the system, this model offers three levels of analysis:

1. Production of scientific results, held to be constructive and oriented towards "success" rather than "truth":

2. Production of production, i.e. investments by scientists and regulation through the scriptures; and

3. Historicity, or reproduction associated with accumulation of capital and progressive reconstruction.

The following discussion is organized according to these levels: it will focus selectively on some of the key concepts involved.

\section{The production of success : constructive tinkering}

According to the language of truth and theory testing, inquiry in the empirical sciences is descriptive: it purports to describe aspects of phenomena as they actually occur. The conception of empirical science as descriptive was often contrasted with a "normative" procedure, i.e. the counterfactual description of what the phenomena would have been under idealized conditions ${ }^{11}$. More importantly such a conception of empirical science is directly linked to scientific realism. The results of scientific inquiry are said to provide generalized descriptions which must be true in order for the theory to be adequate (Suppe, 1974, p. 211). Consequently, theories ascribe reality to the world described by them; for the realist, the aim of science is to provide a literal account of what the world is like (van Fraassen, 1977, ch. 2, pp. 3 ff.) ${ }^{12}$. In contrast, the anti-realist position maintains that the aims of science can well be served without providing such a literal story. In its radical version (i.e. scepticism) ${ }^{13}$, science is regarded as a family of beliefs epistemologically equal to any other family of beliefs ( $c f$. Lakatos 1976, p. 127; Feyerabend, 1970). If taken to mean that the objects one observes, as well as the properties they possess are partly constituted by a system of beliefs (or "Weltanschauung"), scepticism implies an extreme idealism ${ }^{14}$. With a view to what can be explained by 
epistemological scepticism, realism has been called the only conception "that doesn "t make the success of science a miracle" (Putnam 1971, p. 22). Granted that scientific predictions are regularly fulfilled (in certain areas), the question remains whether or not we have to assume a descriptive adequacy of scientific assertions. Why should our interest-geared instrumental ordering of the world mirror an inherent structure of objects?

Responding directly to this question, van Fraassen provides us with the example of the mouse which has the enmity of the cat correctly reflected in its mind and hence runs. Apparently, the reaction of the mouse can be more plausibly explained by pointing out that any species which does not run from its natural enemies no longer exists, thus leaving us only with those that do (1977, ch. 2, p.45). Without trying to re-state a model of biological survival of the fittest to explain the success of science ${ }^{15}$, we can point to evolution in general as an example of the operation of mechanisms which guarantee "hard" success while making postulations of truth and descriptive adequacy both pointless and obsolete. In an article which stresses the imperfection and planlessness of biological evolution, Jacob (1977, p. 1164) recently cited the problem of photoreceptors ("eyes") as one which has been solved over and over again throughout biological evolution, on the basis of at least three different principles (the pinhole, the lens and multiple tubes). Successful and cumulative adaptations resulting from environmental pressure constitute the very core of evolution, yet it would be somewhat bizarre to say that the creations thus arrived at (like the lens eye) are "descriptively adequate" or "truthful" to the reality. After all, such reality provided little more than a stimulus, source material, or an environmental niche to the creation.

To characterize the process of inquiry as "constructive" (as was done in the model sketched above) implies starting from a non-realist position, without denying science its highly productive interaction with reality and without relegating scientific products to the world of beliefs. Empirical observation and experimentation have traditionally been seen as ways of confronting our hypotheses with the reality of what is, and of thereby moving toward a progressively better understanding of nature. However, scientific activities can also be seen as a progressive selection of what works through what has worked in the past and what is going to work under present, idiosyncratic circumstances. Once we see products as selectively carved out, transformed and constructed from whatever is, the claim that we have somehow captured (however incompletely) what is, becomes meaningless and redundant. The question posed by the sceptic as to why our interest-laden instrumental structuring of nature should somehow match the inherent structure of objects can then be answered by pointing to scientific reality as a multiple construction by virtue of its matching the structurings imposed by scientists. To be sure, there is nothing new in the idea that scientists "make" the world in which science is verified, but such ideas have not usually been accompanied by an appropriate rethinking of the research process ${ }^{18}$. In such a rethinking, I submit, "success" would 
take the place traditionally occupied by "truth". Carried by the interested investments of scientific agents, made to work through a constructive mode of operation, and geared to the field and its scriptures, successes have a very mundane quality. In particular, the notion of success (in contrast to truth) is an indexical expression which refers us to the context of a local, idiosyncratic situation. Local contingency spaces mapped out by a variety of factors rule out the one-dimensional rationality which is so readily attributed to scientists ${ }^{17}$. Thus tinkering rather than engineering ${ }^{18}$ suggests itself as a model for the constructive mode of operation associated with success. The existence of tinkering and indexicality can be amply demonstrated in scientific practice, as will be illustrated below.

\subsection{The indexicality of success}

As implied above, the notion of success is tailored to an actual mode of production. Specifically, success is by and for an agent at a particular time and place, and carried by local interpretations. What counts as "true", one will readily admit, depends upon the respective state of knowledge. What counts as success also depends upon the structure of the field, the scientist's position within this structure, and the opportunity space provided by the local environment that makes up the investment site; none of these is independent of the others. In the following example, scientist $\mathrm{K}$. sees an opportunity for success in what is of no interest to H., despite the fact that each is addressing himself to the same problem ${ }^{19}$.

Scientist K., working on protein generation and recovery, expected a plant protein he was currently working with to contain a high amount of toxic solanine. At one point, he decided to make the elimination of solanine a byproduct of other, more pressing experiments. He checked his plan with scientist $\mathbf{H}$. who had worked on solanine for years. $H$. considered $K$.'s method unworkable, but mentioned that $H$.'s laboratory had recently been successful in using an enzymatic procedure with a plant analogous to $\mathrm{K}$ 's. The idea was immediately picked up, and $\mathrm{K}$. later told the observer: "I think I am the only one who got the message from H...and to have understood its implication... $\quad \mathrm{H}$. is too setted on chromatography and his own projects to do this (on his own in his laboratory)... In principle $\mathrm{H}$. would be ready to do things together with me if there is time." $\mathrm{K}$. could not do the necessary experiments on his own since he needed the know-how of the other laboratory. At a later point in time, he added: "I am interested in the problem, but the experiments are too simple (he explained the procedure ${ }^{20}, \ldots$ it's the work of a technician or laboratory assistant... it doesn't challenge me, nor for that reason, H.',

The later development in the above example shows how $\mathrm{K}$. himself loses some 
of his original interest when it turns out that the experiments are "too simple", i.e. inadequate to warrant his own involvement, although still a perfect solution to the original problem. Time involvements are a direct function of the appeal and visibility which can be associated with their representation in the published paper. Since the problem persisted, the original idea was not abandoned, but was given a lower priority and made dependent upon assistance: “...H. hopes to get a student to do this idiotic work...". The position of a student (in the field) is equated here with that of a laboratory assistant.

The second aspect of indexicality, time and place, may not need much elaboration. The role of resources and facilities at the actual site of experimentation will be obvious. No less important is the larger environment in setting the stage for what counts as a success in terms of the relevancies of a given local and historical context. For example, energetic criteria were introduced into the "cognitive" discourse of the laboratory together with the rise of the energy crisis:

An important step in protein recovery is the precipitation of the protein. In general, this is done by using heat coagulation methods. One of the scientists interested in protein recovery had read a paper in which the use of ferric chloride was reported as an effective means of precipitation at room temperature when removing protein from waste water. In the context of an energy shortage, the use of ferric chloride instead of heat coagulation struck him as an excellent alternative: because of the low protein yield of the source material, the energy consumption associated with heat coagulation was enormous. Moreover, avoiding heat coagulation would hopefully result in a less denatured protein, which would be more suitable for human use. The scientist promptly began a series of (successful) experiments, currently in publication. Using the same arguments, he later favored a filtration method over centrifuging in the same test-series.

The following example provides a variation on the theme, observed in the same laboratory:

When testing the suitability of the protein for human consumption, the simplest possible formulation of the number and kind of ingredients was chosen before submitting the samples to various treatments, e.g. fermentation tests. Two reasons were given: to maximize the control achieved over potential factors of influence, and to "just in general" reduce and balance ingredients. The second argument refers to the preference currently shown in certain environments to compositions of carefully selected elements over complex compositions in which the adverse effects of some ingredients may have to be counteracted.

In the latter case, there was no unanimity as to the validity of a criterion embraced mainly by those who were conscious of environmental hazards and of generalized efforts to reduce toxicity. It is interesting to note that the appli- 
cation-oriented laboratory especially installed to conduct tests such as those mentioned above did not support the criterion ${ }^{21}$. This refers us to the third aspect of indexicality: the existence of local, idiosyncratic interpretations. Interpretations have an obvious place in scientific inquiry insofar as the single scientist's perceived interests, investments and evaluations of the meaning of experimental outcomes are concerned. For instance, the progress of negociations over resources resulting from differing interpretations and their associated strategies has been traced elsewhere ${ }^{22}$. What is of interest here is a phenomenon almost completely ignored in the literature on science: research sites develop local interpretations of the scriptures, an exegetical know-how referring to what is meant and how it ought to be translated into practice:

The research institution under observation included several "service" laboratories whose main function was to perform routine analyses of chemical composition required in many research efforts. Coming from another environment, Scientist D. was surprised to find that these tests were commonly performed without replication, apparently under the assumption that such measurements were standardized routines without risks or uncertainties.

D. brought with him a contrary interpretation: measurements become routine precisely because they are important, which means that precision is their foremost requirement. He illustrated his point by citing the fact that single ingredients in a product are reported as percentages of the dry substance of that product. If a product contains $70 \%$ water and $30 \%$ dry substance, and the latter provides the basis for calculating how mituch of a chemical ingredient was found, then the percentage of water in the solution has to be measured very precisely in order to prevent the potential multiplication of errors.

In the laboratory at which $\mathrm{D}$. had worked previously, at least two replications had been made of all routine analyses, and often more. Based on this, D. said: "When I read one figure in the literature, I would automatically assume that I have been confronted with a mean value."

In this case, the clash of two locally developed systems of interpretation became apparent only when the expectations of a scientist transferred from one system to the other were constantly violated. Needless to say, each side stuck to its own interpretation, and scientist $\mathrm{D}$. repeatedly asked the analytical laboratory for the same analysis twice, using different codings for the samples in order not to raise suspicion.

Emphasis on the indexical character of the notion of success suggests that much of the "originality" and distinctive value (in the sense of low probability) of scientific products derives from the idiosyncracies which mark their production. Collins (1975) showed that under circumstances of controversy scientists do not aim for repetition and comparability in cases where one might expect them to. In the present context, distinctiveness is seen as a key prin- 
ciple stressed by scientists under all circumstances ${ }^{23}$. Before looking at this principle, let me briefly discuss what was called the "tinkering" process. Tinkering can characteristically be associated with locally and historically idiosyncratic production.

\subsection{Constructive tinkering}

Tinkering, a mode of operation constrasted with engineering, was recently described as follows:

" - a tinkerer...does not know exactly what he is going to produce but uses whatever he finds around him... to produce some kind of workable object... The tinkerer, in contrast (to the engineer) always manages with odds and ends. What he ultimately produces, is generally related to no special project, and it results from a series of contingent events, of all the opportunities he had...

Often, without any well-defined long term project, the tinkerer gives his material unexpected functions to produce a new object... (These objects) represent, not a perfect product of engineering, but a patchwork of odd sets pieced together when and where opportunities arose..." (Jacob, 1977, pp. $1163 \mathrm{ff}$.)

Though the analogy should not be pushed too far, some of its aspects are illuminating. To avoid misunderstandings, let me stress that the picture of tinkering is not meant to suggest unsystematic or irrational modes of thought and procedure on the part of the scientists. Rather, it is meant to refer us to the "opportunism" of a process which always produces distinctive goods: successful research products. The first aspect of this "opportunism" has already been mentioned. In research, as in tinkering, local opportunities form the basis for investment, and these opportunities are subject to modification through interpretation, negotiation, or straightforward "misuse". For example, because a density-measuring device was broken, a scientist once had the material to be measured centrifuged, and calculated an approximation for density from the difference between volume measurements taken before and after centrifuging ${ }^{2 \downarrow}$. Similarly, a pressure meter, observed in use by chance in one of the laboratories, was subsequently borrowed to determine gas absorption capacity, and sand was once introduced in a series of long-range experiments to simulate a denatured product (but not without leaving scratches on some of the devices used in the series).

The second aspect of "opportunism" linked to tinkering (and one more interesting for the sociologist) refers to the dynamics of the process of research production. In the tinkering of success as a mode of operation, the scientist does not start from a hypothesis which guides him towards the solution of a problem; instead, he starts, from a solution or an opportunity for success from which he moves to actually "make the stuff work". The difference is subtle, 
but consequential, since it is the perceived solutions which push the research process forward, and they push it in whatever direction the opportunity for success may lie. Most of the opportunities for success I came across were prompted by such sources as a result reported in the literature, a discussion with colleagues, or the outcome of an experiment or analysis. In the case of ferric chloride introduced as a means of precipitation (see above), a method which had reportedly worked in another context, was picked up by a scientist during his routine checks of the incoming literature. Asked whether he had searched for such a method, the scientist replied:

"No... I think I was not clever enough originally to see that it would be better to recover protein without applying heat treatment. I probably first read about the $\mathrm{FeCl}_{2}$. One needs stimulation to see..." (italics mine)

In the following example, both an experimental outcome and information obtained in a discussion built into an opportunity for success. A scientist who had worked with the micro-organism Tetrahymena pyriformis W. ${ }^{25}$ was asked about the origin of this research idea:

"The problem is that the protein I was working on according to the literature and according to my amino-acid analyses should have been of high quality... My Tetrahymena tests gave very bad results, however... I had all kinds of explanations, and I was wondering a lot because all were unsatisfying... In the end, I once talked with the people of (he mentioned the producers of the protein in question)... and we talked about something completely different, and they mentioned the relatively high $\mathrm{SO}_{2}$ content of the protein, and I thought that's it... that could be the explanation... Because $\mathrm{SO}_{2}$ inhibits enzyme systems and the Tetrahymena organism is very sensitive and $\mathrm{SO}_{2}$ is risky even for human beings.

Then I started to selectively look at the literature outside my area (Tetrahymena is used in various fields for different purposes)...and it turned out that the organism is sensitive to all kinds of contaminants... Then I got a letter from L. (described as one of the most famous younger scientists in the area) who had worked with Tetrahymena and had claimed that the Food and Drug Administration would soon officially recognize the method (in my area)... Then I thought it would be important to show that the things are not as simple as people think...because in my field nobody knows about the fact that environmental conditions can influence the organism... It (the rest) automatically followed...(I thought) o.k., let's do an experiment taking heavy metals and $\mathrm{SO}_{2}$ - or in general all enzyme-inhibiting systems, because that is what is behind it - and see what happens and show the sensitivity of the organism for ingredients (such as those mentioned)... If a standard method (using Tetrahymena) is issued by the Food and Drug Administration and one doesn't know what influences the growth of the organism (used) that is absurd...", 
Opportunities for success often emerge on occasions which have nothing to do with the research focus they give rise to - as in the above case where the measurement of biological quality which triggered a puzzle was a side result not even reported in the original research. In both examples mentioned, opportunities for success virtually generated the concrete research problem for which they had provided a solution. All new lines of research observed, with one possible exception ${ }^{26}$, seem to have originated in the same way. For example, another research focus involving Tetrahymena pyriformis W. came about when the plot of a growth curve, done by a student using the organism, suggested that the incubation-time might be significantly decreased, and when a discussion with a colleague reminded the respective scientist that it was possible to use the slope-ratio as a predictor of the growth rate. Both "ideas" led to a crucial improvement of a method which was becoming more and more popular. In another area, differences in consistency perceived by the scientist when he manipulated protein samples - and not noticed earlier because the manipulations had been performed by students - alerted him to differences in water absorption capacity. This discovery subsequently led to a special series of experiments and a paper devoted to this variability as well as to a questioning of earlier results which had not taken it into account. In the course of these experiments, the phrase, "this protein really looks like sand", which had once come up in a discussion, gave rise to another line of research based upon comparisons between sand (simulating a fully denatured substance) and protein - a line of research that disproved the ruling "dilution" theory and which it is hoped will eventually establish an alternative theory.

As suggested by the above examples, opportunities for success are often accompanied by long periods of constructively "making things work". Opportunities for success do not operate to eliminate search processes, or outright failures; they act as a driving and orienting force, accounting for the multifaceted picture and constantly changing form of the overall research production. Their power derives from the high probability of success associated with the working out on a practical level of a solution or an asset of information held in stock. In contrast to hypotheses, opportunities for success do not refer us to the imaginary world of tentative explanatory interpretations. They are linked to an interest structure and rest upon a material core - either a result which has been shown to work $\left(\mathrm{FeCl}_{3}\right.$ as a means of coagulation; the sensitivity of Tetrahymena; a growth curve and a slope-ratio method used in another area), or a material difference which is highly suggestive (highly probable differences in water absorption capacity: easily done and conclusive comparisons between protein and a denatured substance). Furthermore, they are workable under given instrumental and organizational conditions. 


\section{The production of production: Investment and regulation}

\subsection{Investments, risks and calculations}

The investments made by an agent in a local investment site (the research organization) were said to set the conditions of production; opportunities for success, when operating as a driving and orienting force, organize those investments around specific topics. It is tempting to suggest, in line with the economic model (and with Bourdieu) that such investments will be made on the basis of calculated risks and returns. However, while such calculations characteristically precede investments which are made when changing from one organization to another, opportunities for success work by means of an immediate appeal, one which precludes elaborate calculations. Since they suggest an obvious advantage, opportunities for success are correctly seized upon with instant commitment. If the research required cannot be tailored to match existing conditions and investments, the "asset" will be stored in the back of the mind and will be pursued occasionally with colleagues deemed knowledgeable in the area. This happened, for instance, in the second line of research involving Tetrahymena pyriformis $W$. mentioned above, where later discussions with colleagues added significantly to the original advantage.

If investments made in research topics do not seem to involve elaborate calculations, they also do not involve high risks for the scientists. Opportunities for success emerge routinely and naturally from the flow of research. The level of risk is kept low by the material, "proven" character of the advantage, and by the fact that often little more is required than to add a few samples to the ongoing experiments ${ }^{27}$, change compositions, request analyses from service laboratories or assign a laboratory assistant to perform the tests. That there are risks involved can be seen when "outdated" experiments are run parallel to a new line of research "to be on the safe side", or when the new line of research does not work out readily and is eventually halted:

From a Russian paper "which hopefully nobody knows here", a scientist inferred that the results of his current tests might be significantly improved by the use of a particular plant juice. He introduced samples which included the juice in addition to his original test-material, but obtained no variance in the results. When various manipulations of the composition and concentration still failed to produce a positive result, the scientist faced spending "at least a few more weeks" on making the tests work. There was an interpretation which could explain the negative outcomes. At the same time, comparisons between the sand and protein samples mentioned above were carried out and showed highly intriguing results which proved "much more worth while". In addition, the scientist had come across further information which suggested that the plant juice procedure was "not really innovative". After pondering the issue for several days, the scientist qualified his effort 
as "only a ploy" for the sake of "selling" well-working results to the agency which financed a contract he held. He then abandoned it, commenting that he had already pursued "too many lines of research anyway".

As in the above case, calculations of risks and returns characteristically occur either in the face of experience which raises the costs of the effort, or when a scarcity of resources makes it necessary to decide between one line of research or another. Once made, investments tend to stablize the effort - Lakatos "protective belts" constructed by scientists around the core of their research program (1970) might be wholly explained by such a stabilization. But what is it which invests an ordinary piece of information with such value that symbolic funds will be committed to it? If investments are made as more or less instant commitments to assets of information which emerge routinely in the process of inquiry, what is it that grounds the positive utility of such assets? While the high probability of success and the "proven" workable character of these assets accounts for the immediacy of an appeal which obviates lengthy calculations, it does not account for the existence of the appeal in the first place.

\subsection{Topical and discriminant value}

To answer the above question, let us focus on the products derived from one year of research work closely scrutinized by the observer, as seen from the perspective of one of the scientists involved:

Beginning with the publications listed "chronologically" in the (extended) Curriculum of the respective scientist up to September 1977, items 27 (the first publication written during the period) to 38 (last entry) appear to be relevant. However, the list has first to be "cleaned up" : publication 27 merely summarizes earlier work, and items 29-30 were written earlier, but were awarded their position because of special considerations related to the purpose for which the Curriculum had been updated. From the 10 remaining items, publication number 36 had to be eliminated, since by the time I looked at the Curriculum (two weeks after it had been updated), numbers 35 and 36 (both listed originally as "in preparation") had been combined. The 9 remaining publications can be sub-divided as follows: $4(28 ; 37 ; 38$; and 39) were considered review articles which included original results assembled by the scientist during that period, as well as before. Written for two journals and two international symposia which published important contributions in book form, the papers characteristically showed only a single author. All other papers had co-authors, reflecting both cooperation inside and outside the research group, and hierarchical power relationships. All were journal articles. Four of the articles were said to include "really innovative results", all of them mentioned earlier as opportunities for success: $\mathrm{FeCl}_{3}$ as a method of protein precipitation (31); the variability of water 
absorption capacity of proteins (33); the comparisons between sand simulating a fully denatured product and various protein concentrations (32); and the behavior and properties of proteins in response to temperature during processing (35). One remaining article was said to assemble, with one exception, routine analysis data on the functional properties of various plant proteins (34).

All papers mentioned were obvious successes; they were considered good enough to be published in a journal or book of high standing, even if they had not as yet passed the review process, or if (as in one case) they had not even been written (37) ${ }^{28}$.

What is the value of writing a review paper? The answer, suggested by various comments made when the papers were written, is simple but nonetheless interesting: 1) the value of the product is topical and stems from coverage of an area which had not as yet been covered or needed to be updated;2) the paper will almost automatically yield a high citation rate, since it spares its readers the effort of searching the literature themselves; 3 ) a review paper will only be written by (or accepted from) an author who has worked in the area himself, thus providing him with ample opportunity to cite and report his own research even if previously unpublished or published in little-known journals; 4) the author of a review paper will be "produced" as a specialist in the area, thereby making his mark as an authority on some special segment of the scriptures; and 5) review papers are often invited contributions which derive part of their appeal from the prestige of the institution or author that "produces" the paper by installing it on the market.

Topical value also sustains the last paper mentioned (34). Although the paper introduced a new measurement technique (and therefore a new property to be measured) into the area, it was said to rest on routine measurements of functional properties which had not been available before in regard to the respective substances. It is interesting to note that the paper was written with the explicit intent of backing the application of its author, who at that time was seeking a position with an institute whose chairman's reputation rested on work with functional properties.

In contrast, the "really innovative" papers rest on what could be called discriminant value: a method of protein recovery was carefully compared with the predominant method and displayed as superior; the ruling "dilution" theory was discredited; and so was the "lipid" theory which attributes the distinctive reactions or protein mixtures in response to temperature and fermentation to the lipid content of the proteins (35). Another method (including the respective measurement device) which has been used "blindly for more than thirty years" was put into question by differences found in the water absorption capacity of the proteins (33). What makes the respective productions "innovative" and "original" in the language of the scientists is their power to discriminate, both in the sense of distinguishing 
between the new product and those relevant in the area, and in the sense of reclassifying the latter as inferior, outdated, or holding only under special conditions.

Both topical and discriminant value relate to the specific characteristics of scientific production, a production in which value is conferred to a product because of its distinctive quality with respect to the scriptures of the area. To paraphrase Godelier, one could say that scarcity is instituted in scientific production ${ }^{20}$ by means of highly idiosyncratic (but non-privative) ${ }^{30}$ conditions of production in which opportunities for generating distinctive products constantly arise and are selected for investments. These investments are regulated by the scriptures of the fields, as can be seen from a close examination of the mechanisms involved.

\subsection{Regulation by the scriptures: affirmative negation}

There are three characteristics of regulation by the scriptures of a field which play a key role in setting the conditions for scientific production 1) a common "language" provides for a generative ordering of the terms in which reality is established and modified ${ }^{31}$; 2 ) the mechanism of negation assures the distinctive quality of the products and a certain rhythm of production and 3) a general ambivalence of relationships and an opacity of products is associated with analogical transference of these products.

1) By attributing a function of generative ordering to the language game of a field, I am not invoking Kuhn's paradigms ${ }^{32}$, nor do I want to bring up the role of socialization or the special institutions of science (although both are of obvious importance). By defining regulation in terms of the scriptures of a field, the focus is first of all shifted towards a fuzzy set of writings consisting mainly of the not-yet-accepted literature relevant in a given area. These writings can be relatively well defined at any given point in time for a category of agents ${ }^{33}$. They are held to operate through a web of connotations, denotations, and contrast-sets of classifications which structure perception and scientific action ${ }^{31}$. It is through these categories (including the non-verbal) ${ }^{35}$ that reality is recognized, ordered, extended analogically and selectively responded to. Classifications which abductively ${ }^{36}$ establish "what is the case" are routinely inserted into the research process, and these classifications are based upon categories present in the scriptures and in natural language. As in natural language, the principle is generative; there is no definite or finite set of categorizations. Scientists play on this generative principle when they respond to the proposal that some substance "is a foam" by saying that "it is really a gel", and later "an aero-gel". As might be expected, generativity is regulated ostensibly by negation.

2) Within the framework of a production oriented toward distinctive products, the control function of the scriptures is one of affirmative negation. In order to distinguish himself, the scientist has two options in confronting what is said 
in the scriptures: he will either be guided in his own production towards alternatives which contrast with some result in the literature, investing his products with discriminant value, or toward an avoidance of existing knowledge claims, drawing from the topical distinctiveness mentioned above. In both cases, what is said in the scriptures (A) is negated in the logical sense through a product which in the relevant respect sets non-A. The space created by opposition, alternation and avoidance is thus much broader than one mapped out by purely contradictional dialectics. Not everything goes, however: blatant repetition and ignorance of the authoritative writings would make it hard to succeed on the market of scientific products ${ }^{37}$. Products which rest upon differences are relational; negation is called affirmative since an A must first be affirmed (whether cited, posited, used as contrast group in an experiment, etc.) before it can be negated ${ }^{38}$. Hence, the curious phenomenon in which a product can be "established" (as measured by citations) through acceptance as well as through criticism.

Although the movement of negation can only be traced through diachronic analyses of the products of a field, observation of scientists at work continuously affords us a glimpse of segments of this movement. The case of the "dilution" and "lipid" theory introduced earlier serves as an example ${ }^{39}$ :

According to the literature, a certain volumetric effect obtained when proteins were mixed with other substances and subjected to fermentation and heat treatment was due to the dilution of the gluten of the mixtures by the proteins (hence "dilution" theory). The scientist involved with these experiments did not quite "believe" in this explanation. Exploring an opportunity for success prompted by the phrase "this protein really looks like sand" (i.e. looks fully denatured), he refuted the theory. In doing so, the focus was shifted from dilution as a non-graded quality of one part of the mixtures, to denaturation as a graded quality of another part, i.e. the protein additives (published in 32).

Volumetric differences between different protein concentrates used as additives were explained in the literature by the differing lipid content of the proteins (hence "lipid" theory). In the course of events, the above scientist came across a paper "from somebody in Australia" whom he had not known before: "He has a completely new lipid theory which seems very plausible. The most important criterion is what happens to the bubbles in the mixture when it is subjected to high temperature (the observer was told)... The guy claims that the differences are not in the mixture but happen only under heat treatment... that the mixture is nothing but a foam, and that the foam stability correlates closely with the volumetric differences." The paper differentiated three kinds of lipids and attributed the effect in question to the interaction between them. By making all these proposals, the author moved from the quantity of one kind of lipids to the interaction of different kinds and from a location of the effect in the mixture in general to a location in one part 
of the treatment. Furthermore he reintroduced the concept of a foam, which had been around for some time in other parts of the literature. Again, the scientist in charge did not quite "believe" in the foam, although at first supporting the lipid part of the paper. Because of his own experiments and as a result of discussions with colleagues, he submitted that the mixture was not a foam but a gel, or more specifically, an aero-gel, and derived the volumetric effect from the surface tension of a gel. At the same time, doubts about the lipid theory began to be supported: a paper found and a lipid expert consulted both claimed that differing extractability of the lipids could account for the different quantities found. Consequently, new lipid determinations were made with a more sensitive technique and promptly established the extractability thesis. In sum, the move was from locating the volumetric effect in one part of the treatment (temperature) and associating it with "a foam" and a diversified lipid theory', to locating the effect on the inside-outside axis (surface tension) of the mixtures and associating it with " $a$ gel" while negating the lipid theory (partly published in 35).

Since the work is still in progress, there is no clearcut end to the example. However, a new move that goes back to the original denaturation experiments is indicated. With the lipid- and dilution theories both ruled out, an alternative theory which explains different volumetric effects in different protein concentrations (not explained by the concept of gel and by surface tension) becomes necessary. As the situation stands now (September 1977), differing degrees of denaturation of the proteins through differential exposure to temperature during protein generation are cited as explaining the effects. Denaturation implies changes in the protein structure. The shift is hence from a negation of the lipid theory to substituting a denaturation theory, and from locating the effect on the inside-outside axis to locating it in the particlestructure. The concept of a gel has not been mentioned recently. Determinations of the protein particle-structures are said to be the next step.

As is obvious from this example, what has been said or written before plays a key role in orienting what will be claimed subsequently. Figure 2 summarizes the movement of negation as exemplified above.

3. Distinctive products carried by movements of negation are not invented from scratch. Not only are scientific products dependent on local resources and contingencies (as argued above), but the hard core of solutions and opportunities for success is also derived mainly from findings in other areas and contexts, from discussions with colleagues, early and unknown literature, etc. As often noted ${ }^{40}$, the scientific system, unlike economic or political systems, relies on the generation of its own system input. Consequently, disproof of one part of the scriptures must at the same time draw heavily upon other parts to provide the necessary background knowledge and source material which justify the negation. Scientists are, to repeat an old point, 


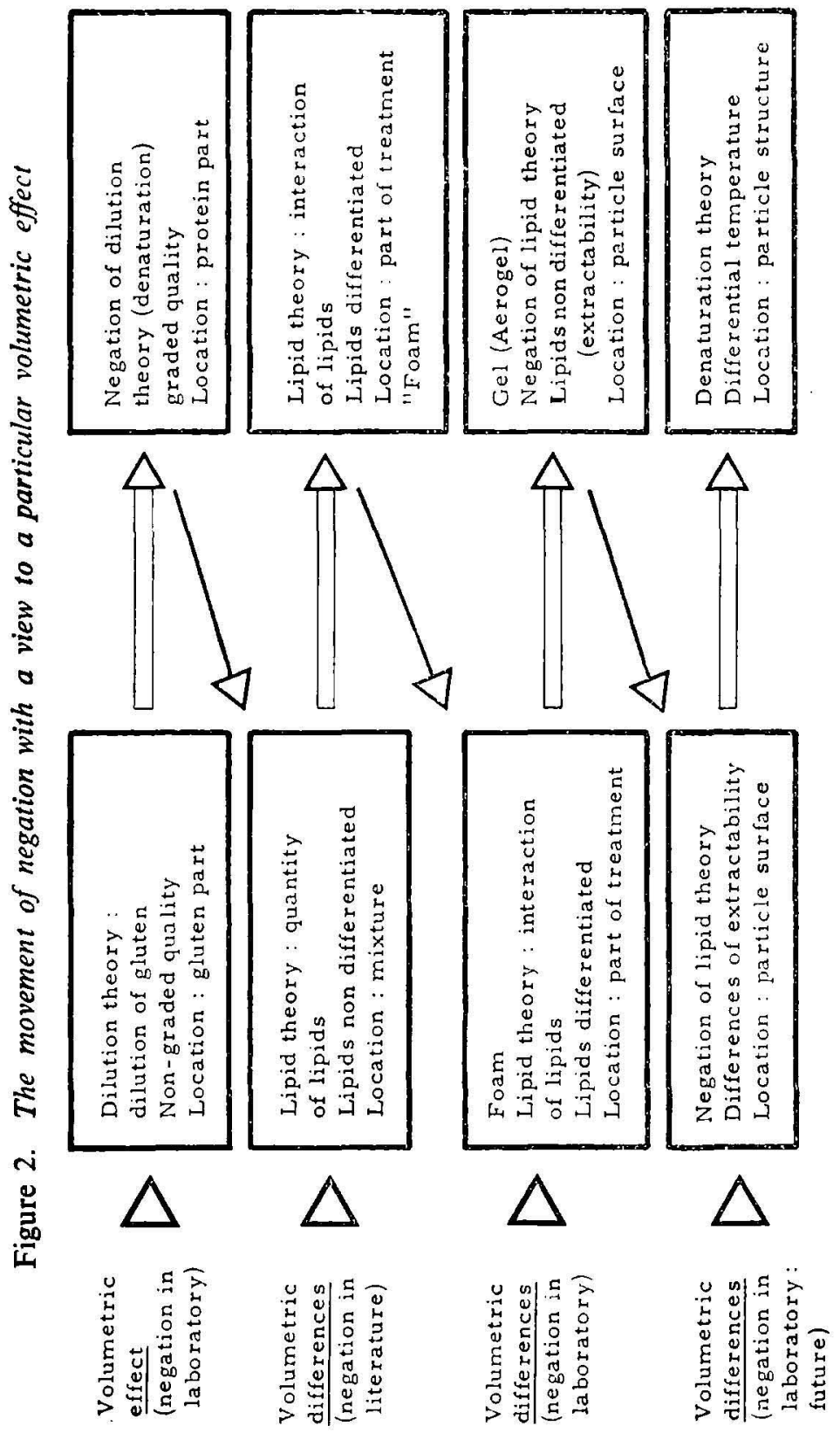


at the same time opponents and accomplices ${ }^{41}$. Unlike the case of personal friends and enemies, these relationships in general can be changed at will and under an utility function. At the level of scientific production, the underlying competitive struggle appears abstracted and generalized. Generalization allows one to change alliances according to what fosters one's own interests on an almost day-to-day basis. What is noteworthy here is the ambivalence of relationships and the opacity of scientific products associated with generalization and negation. Far from being warranted only within the context in which they are presented, scientific results tend to be transferred between contexts possessing some analogical characteristics. Such cases are included in earlier examples, e.g. when the sensitivity of the micro-organism Tetrahymena pyriformis $\mathrm{W}$. to heavy metals established in some areas of microbiology was transferred to the field of plant protein research and used in a research context in which the influence of $\mathrm{SO}_{2}$ on biological value (as measured by Tetrahymena) was analyzed. Analog reasoning, whether in the form of such direct transferences or of metaphors as described by Black (1962) and Hesse (1966) ${ }^{42}$, is a major source of distinctive opportunities for success. The notion of analog reasoning is expounded and exemplified in detail in Latour (1977) and Knorr (1977b). For the present purpose, it will be sufficient to state that the exchange of scientific products is an exchange of scientific "facts", not of papers, and that this exchange operates through what I have called analog transference. If this connection is not made, we are left with a purely (and poorly) sociologistic conception of exchange, as manifest in the respective literature ${ }^{43}$. If we do make the connection, however, we see that exchange is related to scientific production rather than to control and rewards, and can begin to see a link to the historicity of science.

\section{Some speculations on historicity}

As outlined in the beginning, the dynamics of scientific production must be linked to a competitive struggle for scientific capital which takes place through investments made in a field and in a local site of reproduction, i.e. the research organization. This struggle for scientific capital is a struggle for the accumulation of "say" or of "holdings" in the scriptures as indicated by the number of papers, citations received, and ultimately, textbook entries. In accord with the distinctive quality of scientific products, dominance over what is said in the scriptures cannot be gained, in the economic sense, by a simple reappropriation of capital. Appropriation of capital in science implies changing the scriptures; what is produced, to paraphrase Touraine, is historicity ${ }^{44}$. The historicity of science rests with the progressive (re-)constructions that result from the movement of negation briefly sketched in the last paragraph. Progressivity here is not meant to be intensional; as previously implied, nothing is gained by conceiving of science as cutting progressively bigger (and better) pieces out of the pie of "truth" ${ }^{25}$. Instead, science is 


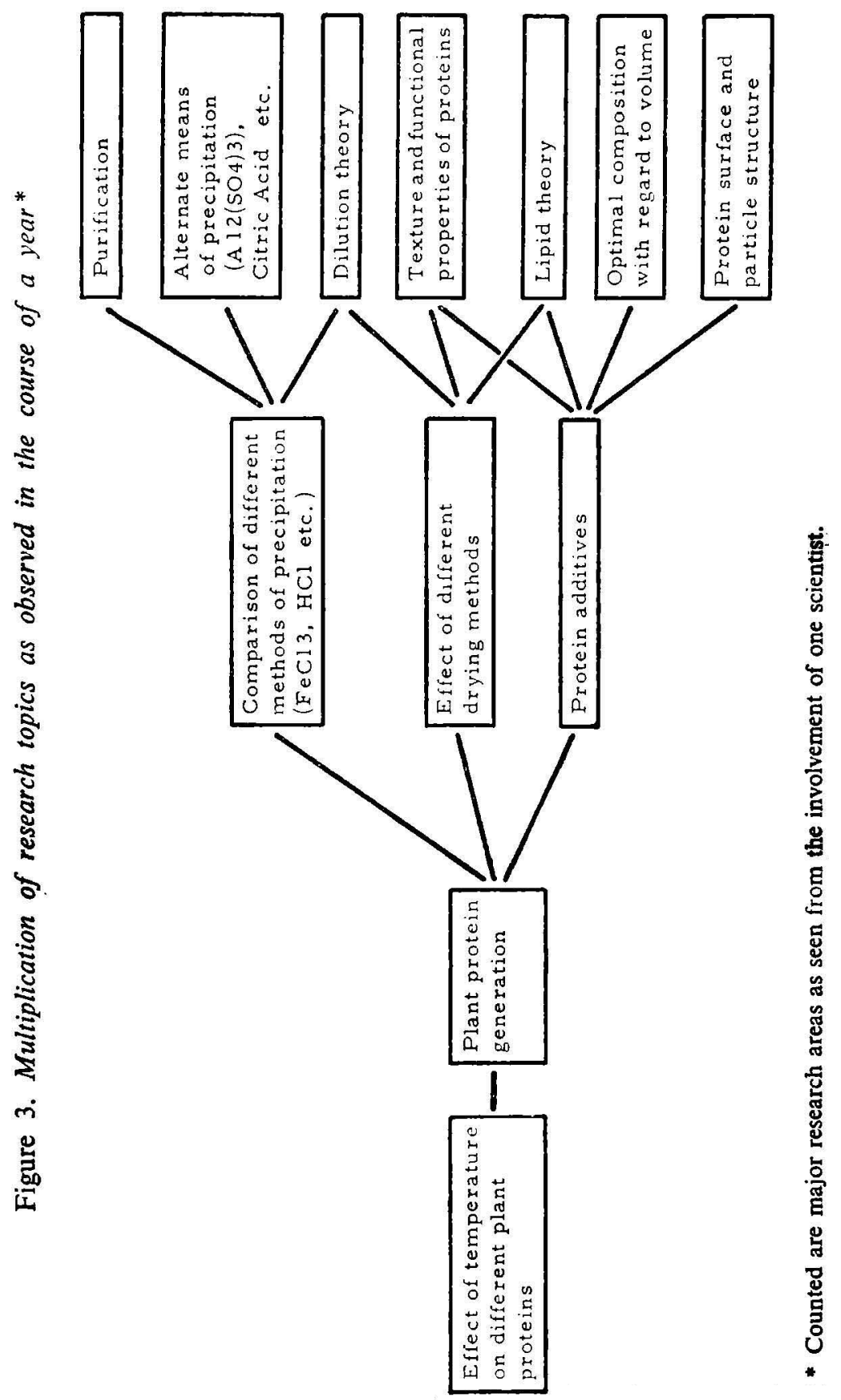


held to move on in an extensional sense: it progressively investigates new referents which are instrumentally constructed within the system itself. Over a period of one year's research work, it is not difficult to see how those referents emerge and become established as a property, a finding, or a fact added to scientific reality. For example, the misuse of a pressure meter to determine the gas absorption capacity mentioned above resulted in establishing the latter as a new functional property of proteins to be measured henceforward in protein analyses. The branching out of research topics which carry along new referents ${ }^{{ }^{* 6}}$ and are routinely generated within a year's research can be seen in Figure 3.

In addition to the extensional meaning given to progressivity, it is important to note that the concept of (re-) construction refers to the mode of production rather than to a mode of evaluation. Evaluation is alluded to when such notions as cross-control, acceptance or critical appraisal are invoked as mechanisms which operate to the advantage of "true ideas" and "universal norms of reason" ${ }^{47}$. Earlier in this paper, scientific production was characterized as drawing from the idiosyncratic opportunities of local research sites as well as from analog transference, and was seen to be regulated by negation. The difference between a production regulated by negation in contrast to control and appraisal is to be found in differences in the locus and dynamics of relevant scientific action. The dynamics of negation and opportunities for success accounts for the anarchy and variability of scientific products ${ }^{\$ 8}$, a fact left unexplained by a dynamics of cross-checking validation. Nowhere in the scientific scriptures do we find the "highest possible efficiency" which Polanyi relates to mutual adjustment and authority, the twin principles of cross-control ${ }^{49}$. Furthermore, most published results cannot be easily re-generated, or validated ${ }^{50}$ - a fact which may be surprising to the outsider. Hence what is selected will not depend on the evaluation of a product in itself; instead, it depends on whether a result fits into the framework of a current undertaking and works out successfully in instrumental manipulation. When actually observing scientists at work, the only sense we can give to the notion of control - except, perhaps, in the rare direct clashes of controversy - lies in the checking implied by reutilization (and modification) in the sphere of production. Controversies highlight the antagonisms within the scientific system; but in general, such antagonism remains diffused and abstracted in a negating mode of production ${ }^{51}$. If we do not find direct control arising from direct antagonism, neither do we find (as various critics of Kuhn have suggested), the consensus or the institutions of consensus-formation which we might expect to operate in critical discourse and evaluation. Agreement in science is not a matter of opinion ${ }^{52}$. It resides in the practice of a mode of (research) production which generates and transforms reality by means of constructive tinkering. The logic of science lies in what is done with reality, and the present paper is an attempt to outline the contours of that logic. 
Karin D. Knorr (born 1944) whose permanent affiliation is the Institute for Advanced Study in Vienna, is presently visiting at the Institute for the Study of Social Change, University of California, Berkeley. Her main research interests are in social studies of science, philosophy of science and in mcthodology. She is coeditor of two recent books: Determinants and controls of scientific development, (with others) (J975); Wissenschaftssteuerung (with H. Strasser) (1976); and has published among others the following contributions in joint volumes: "Konsens und Kumulativität in den Sozialwissenschaften", Kölner Zeitschrift für Soziologie, (Sonderheft Wissenschaftssoziologie), 1975: "Policy makers use of social science knowledge: Symbolic or instrumental?", in : C. Weiss (ed.), Using social research in public policy-making (1977).

\section{Notes}

* I am heavily indebted to the scientists at the observed institution who willingly served as informants and discussants of the data collected; to Bruno Latour and his colleagues at the Salk Institute in San Diego without whom the present paper would perhaps never have been written; to Richard Ogar who kindly edited the paper, and to the Institute for Social Change, University of California, Berkeley, which facilitated my research.

1. Cf. Bourdieu and Delsaut, 1975, and Bourdieu 1975, 1977.

2. The notion of "practice" is used here in the Wittgensteinian sense of a "form of life" (1971).

3. The notion scientific credit is not to be confused with the "recognition" or "reputation" in studies of scientific communities. Credit refers to the sphere of scientific production rather than to the reward system.

4. In contrast to a model which treats "social" and "scientific" (cognitive) pursuits as separate and independent phenomena, the present conception emphasizes their coincidence and inherent interdependence. Implicit or explicit assumptions of independence in regard to the above phenomena are prominent in the literature. For example, Bourdieu accuses Merton of making an artificial and pointless distinction between social and intellectual conflicts (1975, p. 22). Most sociological studies of scientific communities and communication either ignore cognitive variables or annex them to social factors. The relevance of cognitive factors to the respective studies was stressed in Nowotny (1973) and exemplified in Knorr et al. (1975).

5. The system-theory version sees truth as a control value ( $c f$. Luhman, 1971).

6. There is some question as to whether the notion of capital should be defined in terms of the sum total of the agent's relevant competencies, or in terms of the tangible assets in his symbolic profile, i.e. the curriculum entries (including publications and citations). Notwithstanding the fact that the value of these assets is subject to interpretation and negotiation whenever they become an issue, the latter definition has the advantage of being operational. Furthermore, it gives a definite meaning to the notion of "accumulation" of capital.

7. Accordingly, the capital of the organization is not given special attention here, even though I realize that this will be necessary in a more detailed study of the research process.

8. This is amply demonstrated both in hearing and interview procedures, and in the negotiations which usually precede investments (the employment of a scientist, position offers) on both sides.

9. According to Touraine, the historicity of a society can be traced to the existence of a class struggle and the resulting accumulation (1976).

10. In Bourdieu's work on the production of cultural goods, some attention is given to "succession" and "subversion" strategies, said to be associated with low and high risks (and costs) respectively (e.g. 1975, p. $30 \mathrm{ff} ; 1977$ ). 
11. Classical particle niechanics (Suppe, 1974, p. 214) and the neoclassical style of economic thinking (Albert, 1968) as well as the philosophy of science itself provide examples of normative approaches. Classical particle mechanics, for instance, views phenomena as though they were isolated systems of extensionless point masses in a frictionless vacuum.

12. This is not a naive statement of the position which holds that the picture science gives us of the world is a true one. In the above version, the emphasis is on an epistemic attitude. (Cf. van Fraassen, 1977; ch. 2, p. 2 ff.)

13. The version of instrumentalism represented by Toulmin will not be discussed here because of the many objections which can be raised against it (cf. Suppe, 1974, p. 133 ff.).

14. Suppe points out that none of the anaiyses which can be said to imply such an extreme idealism (e.g. Bohm, 1957; Hanson, 1958: Kuhn, 1962, 1970; Feyerabend, 1970) are necessarily committcd to it. It is consistent with their position to affirm that the objects of observation exist and have properties independent of conceptualization. But the nature of the objects observed and the properties they are seen to possess are determined in part by the conceptual frame of the observer (Suppe, 1974, p. $192 \mathrm{ff}$ ).

15. As has already been introduced by Toulmin (e.g. 1970).

16. With the possible exception of Feyerabend, whose historical examples provide valuable insight into the mechanisms of research procedure (e.g. 1975). Besides Feyerabend, there are other prominent examples of this conception of scientific reality as constructed, i.e. Peirce and the Frankfurt school, particularly Habermas. Peirce says, for instance, "we usually conceive Nature to be perpetually making deductions in Barbara. This is our natural and anthropomorphic metaphysics..." (1931-1935, II, p. 713). For Habermas, the "behavioral system of instrumental action" is the "framework which establishes the conditions of the objectivity of possible statements about the real " (1971, p. 126). According to Feyerabend, "scientific theories are ways of looking at the world; and their adoption affects our general bclicfs and expectations, and thereby also our experiences and our conception of reality. We may even say that what is regarded as 'nature' at a particular time is our own product in the sense that all the features ascribed to it have first been invented by us and then used for bringing order into our surroundings" $(1962$, p. 29 ; italics in the original).

17. Even the ethnomethodologists tend to get caught in this trap. Garfinkel (1967, p. 262 ff.) argues that some types of rationality occur exclusively in scientific theorizing, both as "stable properties of actions" and as "sanctionable ideas": logicalness, semantic clarity and distinctness for its own sake, and methodicalness (italics mine). Feyerabend's historical examples already demonstrate that, for some pet theories of the history of science, such ascriptions are untenuble (1970).

18. This is by no means to say that the notion of the engineer as someone who systematically pursues a prespecified goal according to a detailed plan by using raw material and tools which "cxactly fit" his project (Jacob, 1977, p. $1163 \mathrm{ff}$.) correctly reflects reality. The notion of tinkering was used by Lévi-Strauss (1962) and recently by Jacob to characterize biological evolution (1977).

19. Parts of the following example have been used in Knorr, 1977a.

20. This means that it was not only the know-how of the other laboratory, but also a kind of copyright on the idea, which prevented $\mathrm{K}$. from doing the necessary experiments on his own.

21. Part of the reason that this laboratory was not involved in the "suitability" tests although organizationally belonging to the group which did the protein work - was that the tests were not directly oriented towards application (see below). In this connection, the laboratory was not "trusted" sufficiently because of the different criteria and working procedures it embraced. While the facilities of the laboratory were occasionally used by the protein people in the above case, contacts with the members of the laboratory were restricted to occasional information and polite gestures. 
22. I am particularly referring here to the example of a struggle between " $K$ " and " $D$ " for the access to K's large-scale laboratory in Knorr (1977a), where the point is presented in more detail.

23. One might also point out that the nced to evaluate producers rather than products as stressed by Bourdieu (1977) derives from the idiosyncratic nature of the information generated.

24. Since the centrifuging provided for compression under fully controlled and standardized conditions, the idea, inconspicuous as it seemed, was in fact quite ingcnious.

25. The growth rate of the micro-organism when put into specific substances is used as an indicator of the biological value of that substance. The method became popular only very recently with the rise of interest in proteins for which the organism is prinarily used.

26. This exception, in which the research work originated from a more or less vaguely defined problem rather than an opportunity for success, is explained by the fact that the respective scientist had entered a new organization and research group. Both the group and the scientist had refrained from specifying any particular interests in advance, which led to an initial period of search based on a problem rather than a solution.

27. This was the case with the experiments on water absorption capacity and with the comparison between protein and a denatured substance.

28. This should not surprise anyone, given a combination of factors such as workable opportunities for success, heavy data, prestigious co-authors and a prestigious research institution.

29. In his economic anthropology of primitive societies, Godelier says that "everything happens as if primitive societies had instituted scarcity" in the sense that there is generally no production of surplus value even if there are sufficient resources available (1971).

30. Procedures, techniques and even the trade names of measurement devices are at least partly made public under headings such as "method" in the introductory paragraphs of a scientific paper. Such descriptions may well be necessitated by idiosyncratic circumstances of production in which organizational resources, power structures, relevancies imposed by the larger environment and individual strategies, all regulated by the field, combine to promote conditions of low probability.

31. A number of recent works attest to the role of language as a scheme of classification of reality. For a prominent example, see Cicourel (e.g. 1972, 1973).

32. When actually looking at research, the notion of paradigm does not lend itself easily to a definition of the accepted and shared background knowledge of a field - as has been observed by many critics. The institution I studied provided ample opportunity to observe chemical, microbiological, physical, technical and biological "paradigms" at work in the same area, and often at least partly managed by the same scientist. If the notion were applied at all, nothing less than the whole series of disciplines mentioned (and more) would have to be considered as forming one paradigm.

33. Fuzzy borders should not disturb us here; scientists themselves constantly explore and redefine the borders of "relevant "literature. It should also be kept in mind that "the relevant literature of a field" is not independent of the frames of single scientists for whom it $c a n$ be identified.

34. In accordance with Barthes (1974, p. 9) denotations are taken to be "no more than the last of the connotations". In actual research, definite and unequivocal meanings (which could only be mathematical definitions) appear to be either non-existent or irrelevant. Furthermore, local interpretations play a key role even if concepts are clearly defined in terms of measurement operations. According to ethnomethodological results this is not implausible.

35. In a recent article, Ferguson (1977) traced the importance and the history of nonverbal thought in technology, beginning with Renaissance picture books. However, there is an 
unfortunate tendency to identify science with "unambiguous verbal descriptions" and to contrast it with the "thinking with pictures" of the engineer (p. 828, 834). In the institution I studied, almost none of the researchers had a background in engineering; yet there was a specially equipped "art-shop" and a photography laboratory which exclusively dealt with designing, copying and printing illustrations. Since much of the discussion, interpretation and analysis I observed was organized around illustrations, it presumably involved nonverbal imagination. Needless to say, there is a strong emphasis on non-verbal representations in all kinds of publications.

36. According to Peirce, abduction is a form of inference which combines induction and deduction. Based upon something seen, a rule is invented to explain the result, whereupon what is the case is inferred from the rule and the result. By "result", Peirce means an unpredicted fact which requires interpretation (1931-1935, V, p. 171).

37. Pure repctition, in science as in art, catapults the product out of the relevant market. While ignorance seems to succeed in art - ("naive" art), "naive" science has not yet been invented. However, ignorance must be seen to rest more with the product than with the producer. Thus the occasional success of an outsider, not knowledgeable in a field, will not be surprising if the product remains within the sphere created by negation.

38. This may be a difference between science and haute couture (but also art!) as described by Bourdieu (1977). While the products of the couturiers do seem to be relationally distinctive, opponents will not in general be affirmed.

39. It should be kept in mind that the following example, reconstructed and summarized, looks much more systematic and chronological than it appears in the observation protocols.

40. Recently, the point was made by Luhman (1971) and Bourdieu (1975).

41. This particular notion is used in Bourdicu (1975, p. 39).

42. The simile "this protein looks like sand" mentioned earlier exemplifies the case for the present context.

43. A much-cited key work representing such a conception of exchange is Storer (1966).

44. Touraine relates the historicity of a society (its capacity to transform itself) to the existence of class relationships, accumulation, and the existence of a struggle for the direction of the historicity $(1976$, p. 886,897$)$.

45. The point has been discussed extensively in connection with Kuhn's theory of scientific revolutions which portrays scientific development as a succession of tradition-bound periods punctuated by non-cumulative breaks $(1970$, p. 208). Popper, in contrast, had invoked the image of the mountain climber who never quite sees the summit but progresses steadily.

46. New referents here range from "familiar" pieces of reality approached from a specific scientific perspective (certain plants approached biochemically with a view to protein generation) to new relationships and phenomena of inquiry (volumetric differences obtained for different plant proteins).

47. The notion of cross-control recently invoked by Bourdieu (1975, pp. 31-35) goes back to Polanyi's ideas about mutual self-coordination and authoritative censorship among scientists (c.g. 1969, pp. $49 \mathrm{fl} .83 \mathrm{ff}$.). Discussions of "rational appraisal" are likely to be found in philosophy of science, particularly among critical rationalists. For a summary of the results of this school, see Lakatos (1970).

48. This anarchy and variability can be seen from a study of the literature of a scientific field. It is partly traced in Knorr, 1977c.

49. Polanyi defines self-coordination or mutual adjustment in terms of individual scientists who set themselves problems and pursue them with a view toward results already achieved by other scientists. Mutual authority is said to consist in the fact that each scientist is sub. ject to both criticism and appraisal by others - the basis for the formation of scientific opinion (1969, pp. 84-85). Polanyi never bridges the gap between production and validation with a vicw to scientific progress, a gap at least partly reproduced in Kuhn (1970). 
50. According to the scientists themselves, constraints in terms of space prevent elaborate descriptions of what was done and how it was done in current scientific papers. Furthermore, the information presented in a published paper is sometimes "classified": scientists have a plausible reason to withhold at least part of their know-how ( $f$. Knorr, 1977c).

51. This notion holds despite the fact that criticism may be voiced at various occasions, or find a place in subtle turns of formulation in the scientific paper (e.g. Latour and Fabri, 1977). In the above context, criticism is relevant only insofar as it helps to orient scientific change. In those terms, I maintain, the mechanism is one of negation, and it resides in a mode of production rather than a mode of appraisal.

52. To borrow from Wittgenstein $(1971$, p. 139), one could say the agreement is one of a form of life rather than of opinion. Though Kuhn invokes Wittgensteinian notions (e.g. 1970, p. 45) and seems to conceive of a paradigm as a form of life, the distinction between scientists as producers and validators is maintained. Consequently, "consensus" at times comes close to being a matter of opinion, as reflected in the discussions of criteria of rational appraisal which come up at various points in reviews of Kuhn's theory (cf. Lakatos, 1970).

\section{References}

Albert, $\mathrm{H}$.

1968 "Modell-Platonismus. Der neoklassische Stil des oekonomischen Denkens in kritischer Beleuchtung", in: E. Topitsch (ed.). Logik der Sozialwissenschaften. Köln/Berlin, Kiepenheuer und Witsch.

Barthes, R.

1974 S/Z: An essay. New York, Hill and Wang.

Black, M.

1962 Models and metaphors. Ithaca, NY, Cornell University Press.

Bloor, D.

1976 Knowledge and social imagery. London, Routledge and Kegan Paul.

Bohm, D.

1957 Causality and chance in modern physics. London, Routledge and Kegan Paul.

Bourdieu, P.

1975 "The specificity of a scientific field and the social conditions of the progress of reason", Social science information $14(6)$ : 19-47.

1977 "La production de la croyance : Contribution à une ćconomie des biens symboliques", Actes de la recherche $13: 3-43$.

Bourdieu, P.; Delsaut, Y.

1975 "Le couturier et sa griffe : Contribution à une théorie de la magie", Actes de la recherche $1: 7-36$.

Cicourel, A.

1972 "Cross modal communication", in: R. Shuy (ed.). Linguistics and language science. Washington, DC, Georgetown University Press. (Monograph 25.)

1973 Cognitive sociology. London, Macmillan.

Collins, H.M.

1975 "The seven sexes: A study in the sociology of a phenomenon or the replication of experiments in physics", Sociology 9(2): 205-224.

Ferguson, E.S.

1977 "The mind's eye: Nonverbal thought in technology", Science 197 (4306): 827836. 
Feyerabend, P.

1962 "Explanation, reduction and empiricism", in : H. Feigl; G. Maxwell (eds.). Minnesota studies in the philosophy of science, vol. 3. Minneapolis, University of Minnesota Press.

1970 "Against method", in: M. Radner: S. Winokur (eds.). Mimmesota studies in the philosophy of science, vol. 4. Minneapolis, University of Minnesota Press.

1975 Against method. London, NLB.

Fraassen, B. van

1977 The argument concerning scientific realism. Los Angeles, University of Southern California. (Philosophy of science lectures, mimeo.)

Garfinkel, $\mathrm{H}$.

1967 Studies in ethnomethodology. New York, Prentice-Hall.

Godelier, $M$.

1971 L'Anthropologie, science des sociétés primitives? Paris, Denoël.

Habermas, J,

1971 Knowledge and human interests. Boston, Beacon Press.

Hanson, N.R.

1958 Patterns of discovery. Cambridge, Cambridge University Press.

Hesse, $M$.

1966 Models and analogies in science. Indiana, University of Notre Dame Press.

Jacob, F.

1977 "Evolution and tinkering", Science 196: 1161-1166.

Knorr, K.D.

$1977 \mathrm{a}$ "The research process: Tinkering of success or approximation to truth? Preliminaries for a theory of scientific practice". (Submitted.)

$1977 \mathrm{~b}$ "Reasoning and relativism: A constructivist synthesis for science". The Salk Institute, San Diego. (Paper presented at the Symposium on the Analysis of Scientific Discourse.)

1977c "Icons and scripts: On the relationship between research and publications in science". Institute for the Study of Social Change, University of California, Berkeley. (Mimeo.)

Knorr, K.D.; Strasser, H.; Zilian, H.G. (eds.)

1975 Determinants and controls of scientific development. Dordrecht, D. Reidel.

Kuhn, T.

1962 The structure of scientific revolutions. Chicago, University of Chicago Press.

1970 The structure of scientific revolutions, 2nd edition, Chicago, University of Chicago Press.

Lakatos, I.

1970 "Falsification and the methodology of scientific research prograns", in:

I. Lakatos; A. Musgrave (eds.). Criticis:t and the growth of knowledge. Cambridge, Cambridge University Press.

1976 "Understanding Toulmin", Minerva 14(1): 126-143.

Lakatos, I.; Musgrave, A.; (eds.)

1970 Criticism and the growth of knowledge. Cambridge, Cambridge University Press.

Latour, B.

1977 "Accumulation and circulation of scientific credit. A model for guiding a comprehensive sociology of science". The Salk Institute, San Diego, (Mimeo.) 
Latour, B.: Fabri, P.

1977 "La rhétorique du discours scientifique", Actes de la recherche 13: 81-95.

Latour, B.; Woolgar, S.

1978 Science in the making. Los Angeles, Sage.

Lévi-Strauss, $C$.

1962 La pensée saurage. Paris, Plon.

Luhmann, $\mathrm{N}$.

1971 "Selbststeuerung der Wissenschaft", in: Soziologische Aufklaerung. Opladen, Westdeutscher Verlag.

Mendelsohn, E.

1977 "The social construction of scientific knowledge", in: Sociology of the sciences vol. 1. Dordrecht, D. Reidel.

\section{Mitroff, I.I.}

1974 The subjective side of science. Amsterdam, Elsevier.

Nowotny, H.

1973 "On the feasibility of a cognitive approach to the study of science", Zeitschrift für Soziologie $2(3)$ : 282-296.

Peirce, Ch.S.

1931- Collected Papers. Ch. Hartshorne; P. Weiss (eds.). Cambridge, Harvard 1935 University Press.

Polanyi, M.

1969 Knowing and being. Essays by Michel Polanyi. Chicago, University of Chicago Press.

Putnam, H.

1971 Philosophy of logic. New York, Harper and Row.

Storer, N.

1966 The social sy'stem of science. New York, Holt, Rinehart and Winston.

Suppe, F. (ed.)

1974 The structure of scientific theories. Urbana, University of Illinois Press.

Toulmin, S.

1970 "Does the distinction between normal and revolutionary science hold water?". in: I. Lakatos; A. Musgrave (eds.). Criticism and the growth of knowledge. Cambridge, Cambridge University Press.

Touraine, A.

1976 "Huit manières de se débarrasser de la sociologie de l'action", Social science information 15 (6): S79-903.

Wittgenstein, L.

1971 Philosophische Untersuchungen. Frankfurt-am-Main, Suhrkamp. 